\title{
DIAGNOSIS OF POSTTRAUMATIC ARTERIOVENOUS FISTULA USING CT ANGIOGRAPHY: A CASE REPORT
}

\author{
Durim Cela $^{1^{*}}$, Ariana Strakosha ${ }^{2}$, Iva Rudi ${ }^{1}$

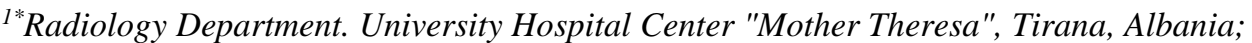 \\ ${ }^{2}$ Nephrology Department. University Hospital Center "Mother Theresa", Tirana, Albania; \\ *Corresponding Author Durim Cela, e-mail: durimcela@gmail.com;
}

Received March 2020; Accepted May 2020; Published June 2020;

DOI: https://doi.org/10.31407/ijees10.223

\begin{abstract}
Introduction: Injuries of the extremities can result in the development of arteriovenous fistula. There is a significant variability in clinical presentation and often prove difficult to detect. A case report: This is a case report of a 26 years old man, who presented with a pulsatile mass on the left leg, without significant clinic and with a history of a stab wound to the left upper thigh 5 years earlier. An ultrasound scan revealed a communication between femoral artery and vein, also a sacular dilatation of the femoral artery. An Angio-CT was performed for a further diagnostic evaluation and confirmed an $6.6 \mathrm{~cm}$ venous varix of the left femoral vein and early opacification of the vein due to an AV fistula from the superficial left femoral artery. Conclusion: A CTA and an ultrasound scan should be performed when a vascular abnormality is suspected in a patient with a history of trauma in close proximity to major vessels.
\end{abstract}

Keywords: traumatic arteriovenous fistula, arterial injury. 